\title{
Spatial Interactions in Multiple-Use Forestry and Substitution and Wealth Effects for the Single Stand'
}

\author{
Stephen K. Swallow \\ Department of Resource Economics, University of Rhode Island, Kingston. Rhode Island 02881 \\ AND \\ DAVID N. WEAR
}

USDA Forest Sercice, Southeastern Forest Experiment Station and School of the Environment, Duke Unicersity, Research Triangle Park, North Carolina 2770?

Received December 17, 1991; revised August 24, 1992

\begin{abstract}
Forestry models often ignore spatial relationships between forest stands. This paper isolates the effects of stand interactions in multiple-use forestry through a straightforward extension of the single-stand model. Effects of stand interactions decompose into wealth and substitution effects and may cause time-varying patterns of resource use for a forest stand. Simulations illustrate that a stand's role, even in steady-state, may alternate an emphasis on timber with an emphasis on nontimber. Optimal management plans differ substantially, depending on whether the manager values nonmarket goods from neighboring stands. The model offers insights for improving heuristic forest-level optimization models in current usage. 1993 Academic Press. Inc.
\end{abstract}

\section{INTRODUCTION}

Single-stand models of forest management. particularly analyses following Faustmann [7] and Hartman [12], are simultaneously criticized for oversimplification and exploited for additional insights into forest economics (Bowes and Krutilla [2, 33, Heaps [13], Paredes and Brodie [26], Snyder and Bhattacharyya [30]). The strength of single-stand analyses lies in analytical tractability and intuitive clarity, while the weakness lies in disregarding stand interactions paramount to the forest-level multiple-use problem. Developing an intuitive understanding of multiple use at the multi-stand or forest level remains an active area in resource economics research. This paper enhances an intuitive understanding by developing a single-stand, multiple-use model that incorporates interactions with surrounding stands.

The present analysis lies as an intermediate behveen Hartman's [12] analysis and Bowes and Krutilla's [2, 3] relatively comprehensive forest-level analyses. This paper complements Bowes and Krutilla's [2, 3] analysis by (i) focusing on a single stand and its interactions with nearby stands and (ii) consistently retaining the

'This research was supported by funds provided by the USDA Forest Service. Southeastern Forest Experiment Station. Economics of Forest Protection and Management Unit, Research Triangle Park. NC, and by the Rhode Island Agricultural Experiment Station (RI AES). All opinions belong solely to the authors, implying no endorsement by any funding agency. The authors are grateful for the numerous. constructive comments from three referees and an Associate Editor. This paper is RI AES Contribution 2713. 
locational identity of each stand. This approach enables a thorough analysis that clarifies how stand interactions affect optimal harvest ages.

Evaluators of forest management planning target consideration of bio-physical consequences and spatial or geographic relationships among stands $[6,9.16,21]$ as weaknesses in the current analysis. In fact, some public land managers face a volatile debate concerning the role of spatial interactions and the future of local timber industries $[18,33]$. The debate involves the mandate that public managers optimize benefits of all types and whether that mandate admits impacts and nontimber outputs from adjacent lands.

The model allows a fundamental analysis of these bio-physical and spatially dependent consequences. Bowes and Krutilla $[1-3]$ consider similar issues, but emphasize the mix of stand ages within a whole forest. The present model is complementary to that of Bowes and Krutilla because they too recognize that the unharvested portions of the total forest may still impact a harvest decision. However, this paper focuses on a single stand, explicitly tracks the harvest decisions for a specific location. explicitly identifies the locations that impact a specific stand, and thereby provides a direct and intuitive basis for understanding, in more rigorous detail. many substantive.implications of stand interactions.

In this paper, the second section incorporates the condition of neighboring stands directly into a single-stand model [12]. The approach is loosely analogous to disaggregating an industry (the total forest) into firms (the individual stands) in order to evaluate external interactions among firms from the perspective of a single firm. The third section presents simulation results based on data from the Lolo National Forest in western Montana. Results illustrate qualitive departure from the analysis of a single stand in isolation. While a steady-state cycle arises, the adjustment path is sensitive to initial conditions. The fourth section places the present model in the context of some forest-level models in current use: for example, the present model offers a tool to identify "adjacency constraints" [29] consistent with landscape ecology [8, 32]. The concluding section highlights the potential contributions to forest management policy.

\section{A SINGLE STAND IN THE FOREST}

For ease of exposition, the analysis builds directly from Hartman's [12] simple model that treats a stand's outputs as independent of all other 'stands and dependent only on the age of the focal stand. In that case, Hartman showed that the optimal rotation age balances the marginal benefits of delaying (MBD) a harvest, in order to capture additional timber growth and nontimber flows, with the associated marginal opportunity costs (MOC) from the delayed receipt of timber revenues and benefits of all future rotations. The present model incorporates a measure of the condition or age of nearby stands but still focuses on the rotation age for a specific stand that other locationally unique stands impact.

Starting with bare ground, the forest management objective remains to maximize the net present value, $N$, of timber plus nontimber benefits produced through an infinite series of rotations on a single-forest stand

$$
N=\max _{\left\{T_{i} \geq 0\right\}} \sum_{i=1}^{\infty}\left\{p V\left(T_{i}\right) e^{-r T_{i}}+\int_{0}^{T_{i}} a(t, \tau(i, t)) e^{-r t} d t\right\} e^{-r \sum_{j}^{i}=i T_{i}}
$$


where $T_{1}$ is the age of the forest stand at the time of harvest $i$; timber benefits equal the net price of timber, $p$, times the volume harvested, $V$; nontimber benefits or amenity values flow at rate $a(t, \tau)$, which depends on the age of the stand. $t$, as well as the ages of neighboring stands, $\tau(\tau$ may represent a vector of ages on several neighboring stands); and $r$ is the appropriate discount rate.' In (1). the terms in braces \{ \} quantifies the total benefits of one rotation in the stand, discounted to the beginning of that rotation."

Equation (1) extends the single-stand model by explicitly incorporating the ages of neighboring stands, $T$, as parameters of the amenity function. To clearly develop the implications of this extension, the discussion assumes a dichotomous forest with two stands, the focal stand modeled in (1) and a neighboring stand representing "the rest of the forest." In this case, i represents the age of a single neighboring stand (a scalar). ${ }^{4}$ From the perspective of the focal stand, the management pattern or rotation sequence on the neighboring' stand remains exogenous. The owner of each stand manages for timber plus any contribution that nontimber outputs from their stand make to their own utility. For example. if the neighboring owner considers only timber benefits. then the neighboring stand would follow a Faustmann rotation plan. This model provides a simple foundation for understanding forest models where all stand interactions become internal $[2,3]$.

From the exogenous rotation sequence on the neighboring stand. each age t during rotation $i$ for the focal stand corresponds to a particular age on the neighboring stand, $\tau(i, t)$. The argument $i$ in $\tau(\cdot)$ is shorthand for the management history on the focal stand because real time (calendar time) covers all previous rotations through the end of rotation $i-1$. That is. the age $t$ of the focal stand during rotation $i$ depends on all previous rotation ages.

$$
t=t\left(s^{\prime}\right)=\int_{0}^{s^{\prime}} d s-\sum_{j=1}^{i-1} T_{j},
$$

where $s^{\prime}$ is the actual (calendar) amount of time since management started and $i-1$ rotations are complete by $s^{\prime}$. Figure la shdws $\tau(\cdot)$, where a clearcut occurs when the neighboring stand ages to $\tau^{*} ; \tau(i, t)$ is piece-wise continuous with slope one and $\tau\left(i-1, T_{i-1}\right)=\tau(i, 0)$ along the continuous pieces. ${ }^{5}$

In (1), the benefits depend on the exogenous state variable $\tau$, which may differ after each harvest, so that, in general, any steady state is cyclical. Such a cyclical steady state involves a repeating sequence of $n$ harvest ages. $\left\{T_{k}^{\prime}, \ldots, T_{k+n}^{\prime}\right\}$, where the condition on the neighboring stand is the same before and after that harvest sequence, $\tau(k, 0)=\tau(k+n I-1.0)$.

Model (1) captures the effects of shifting the focal stand's age relative to a neighboring stand's age (affects from $a_{\tau}$ ). These effects become clear by decom-

${ }^{2}$ If $a(t, \tau)=a(t)$ for all $\tau$, then this model becomes Hartman"s [12].

'Some authors include regeneration and management costs (14. 15. 24, 28. 30], but this paper omits such costs. These costs may alter the optimum rotation age(s), but they do not affect the general illustration of the effects of stand interactions.

'However. the specific location of that neighboring stand affects its interacuons with the focal stand, so that ceteris paribus, a neighboring stand on the south border would have different effects than those of any other stand within the same ecosystem (such as one on the north border). The focal-neighbor dichotomy is primarily an expositional conventence.

'Often, the discussion ignores points of disconinuity in - 

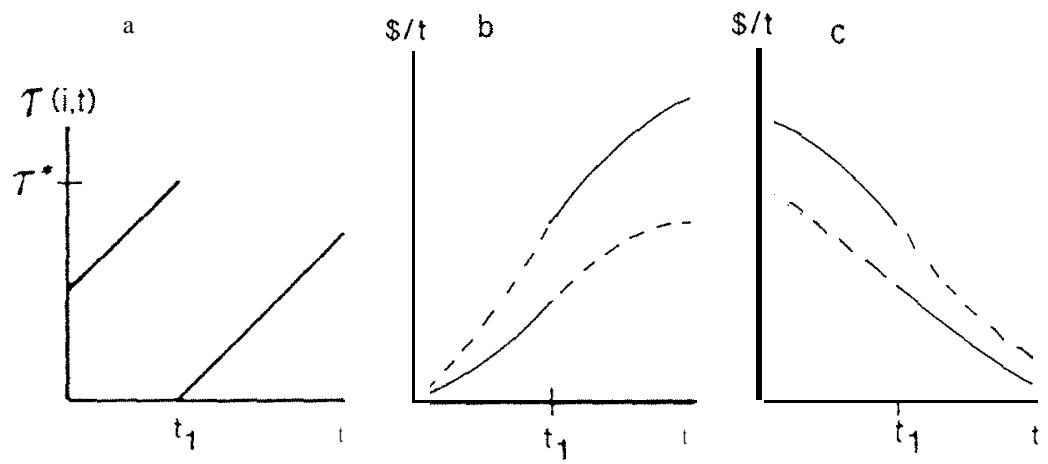

FIG. 1. Relationship between the condition of the neighboring sland and the flow of amenty benefits from the focal stand. The figure assumes that the two stands are substitutes as sources of nontimber goods. (a) Focal stand age $t$ relative to the neighboring stand age $r(l, l)$ during focal rotation $i$. (b, c) Example nontimber benefit functions on the focal stand, illustrating the effects of a neighboring harvest occurring at age $t$, on the focal stand.

posing the management problem (1) into a sequence of rotation decisions from rotation $i$ onward. To this end, define $N(-(i, 0))$ as the net present value of rotations on the focal stand. valued just after harvest number $i-1$ and given that the state (age) $-(i, 0)$ on the neighboring stand exists at the start of rotation $i$ on the focal stand. Further, denote $N^{*}(\tau(i, 0))$ as the optimum value of $N(\tau(i, 0))$, where this optimum obtains from the current decision. the choice of harvest age $T_{i}$ for rotation $i$. In choosing the optimum age $T_{i}$, the forest manager must account for the impact of the current decision on the age of the neighboring stand, $\tau(i+1,0)$, at the start of the next rotation. Then, one may represent the sequential decision process as a dynamic program [11] that links the sequential optimization problems through the impacts on $\tau$.

$$
\begin{aligned}
& N^{*}(\tau(i, 0)) \\
& \quad=\max _{\left\{T_{i} \geq 0\right)}\left\{p V\left(T_{i}\right) e^{-r T_{i}}+\int_{0}^{T_{i}} a(t, \tau(i, t)) e^{-r t} d t+N^{*}(\tau(i+1,0)) e^{-r T_{i}}\right\} .
\end{aligned}
$$

That is, taking each rotation in succession, the manager attempts to optimize the contributions from the current rotation plus the benefits from future rotations. The dynamic programming formulation (3) facilitates an explicit graphical and empirical evaluation of stand interactions. From formulation (3), the necessary condition for optimal rotation age $T_{i}$ is

$$
\begin{aligned}
& p V_{T}\left(T_{i}\right)+a\left(T_{i}, \tau\left(i, T_{i}\right)\right)-r p V\left(T_{i}\right)-r N^{*}(\tau(i+1,0))+N_{\tau}^{*}(\tau(i+1,0)) \\
& \quad=p V_{T}\left(T_{i}\right)+a\left(T_{i}, \tau\left(i, T_{i}\right)\right)-r p V\left(T_{i}\right)-r N^{*}\left(\tau\left(i, T_{i}\right)\right)+N_{\tau}^{*}\left(\tau\left(i, T_{i}\right)\right) \\
& \quad=0 .
\end{aligned}
$$


with the second-order sufficiency condition

$$
\begin{aligned}
& p V_{T T}\left(T_{i}\right)+a_{T}\left(T_{i}, \tau\left(i, T_{i}\right)\right)+a_{\tau}\left(T_{i}, \tau\left(i, T_{i}\right)\right) \\
& <r p V_{T}\left(T_{i}\right)+r N_{\tau}^{*}\left(\tau\left(i, T_{i}\right)\right)-N_{\tau}^{*}\left(\tau\left(i, T_{i}\right)\right)
\end{aligned}
$$

when $\tau_{t}\left(i, T_{i}\right)$ equals 1 and where the middle line of (4) uses the equality of $\tau(i+1,0)$ and $\tau\left(i, T_{i}\right) \cdot{ }^{6}$ In (4) the last two terms quantify the impacts of the ith harvest decision on the value of future rotations, with

$$
-r N^{*}(\cdot)=-r \sum_{k=i+1}^{\infty}\left\{p V\left(T_{k}\right) e^{-r T_{k}}+\int_{0}^{T_{k}} a(t, \tau(k, t)) e^{-r t} d t\right\} \cdot \alpha_{i+1, k-1}
$$

capturing the opportunity cost of discounting future rotations and-with

$$
N_{\tau}^{*}(\cdot)=\sum_{k=i+1}^{\infty}\left\{\int_{0}^{T_{k}} a_{\tau}(t, \tau(k, t)) e^{-r t} d t\right\} \cdot \alpha_{i+1, k-1}
$$

capturing the opportunity cost of shifting focal rotations relative to neighboring rotations. Definitions (6) correspond to necessary conditions for (1), where discount factors $\alpha$ are defined for a subset of rotations.

$$
\alpha_{y,:}=\exp \left(-r \sum_{j=y}^{z} T_{j}\right), \quad 0 \leq y-1 \leq z<\infty,
$$

with $\alpha_{y, y-1}=1$ and $\alpha_{y, y+s} \cdot \alpha_{y+s+1 z}=\alpha_{y, z}$ for any nonnegative integer $s$.

To further distinguish implications of stand interactions on management of a single stand, respectively define the marginal benefit of delay curve, MBD, and the marginal opportunity cost of delay curve, MOC, by

$$
\begin{aligned}
& \mathrm{MBD},=p V_{T}(t)+a(t, \tau(i, \mathrm{t})) \\
& \mathrm{MOC},=r p V(t)+r N^{*}(\tau(i, t))-N_{T}^{*}(\tau(i, t))
\end{aligned}
$$

for rotation $i$ on the focal stand of age $t$, Then necessary condition (4) requires the optimal harvest age, $T$, , to balance the marginal benefit of delay with the marginal opportunity costs of delay, where the MOC of a delay includes the foregone return on the immediate harvest $\mathrm{i}$ and on the timber plus nontimber benefits from all future rotations (see (6)). The sufficiency condition (5) implies that, up to the optimal age $T_{i}$ in (4), MBD exceeds MOC.

Dynamic programming formulation (3) permits a graphical comparison of marginal benefits and opportunity costs (8) for rotation age $T_{i}$ (cf. Clark [5], Nartman [12], Newman [24]). At the optimal $T_{i}$, condition (4) implies that MBD, = $\mathrm{MOC}$, and condition (5) implies that MOC, intersects MBD, from below.

\footnotetext{
${ }^{6}$ Points of discontinuity in $\tau(\cdot)$ may force a harvest on the focal stand to coincide with a harvest on the neighboring stand. In such a case, the optımum $T$ will not satisfv (4), but prior to this optımum. marginal benefit of delaving the harvest (MBD) exceeds the marginal opportunity cost (MOC) of that delay. while after this optimum. MOC exceeds MBD
} 


\section{Graphical Analysis for the Singie Stand}

The single-stand focus, with condition (4), permits a geometric analysis of management implications. The key lies in the relationship between amenity benefits $\mathbf{a}(\cdot)$ and the condition of the rest of the forest, as represented by neighboring age $\pi(\cdot)$ (cf. Fig. la to Figs. lb and $1 \mathrm{c}$ ). Figure lb illustrates amenity benefits that rise with the stand's age, such as scenic value or habitat for wildlife adapted to old-growth forests. Figure $1 c$ represents an opposite extreme where nontimber benefits decrease with forest age. such as water yield or grazing. Several authors illustrate amenity functions that mix aspects portrayed here $13, \mathrm{pp} .110-111$ et. seq.; 4; 10, pp. 79-84, 317-320; 31], but these extremes (Fig. 1) adequately support discussion.

In Figs. $\mathrm{lb}$ and $\mathrm{lc}$, amenity benefits from the single, focal stand and amenity benefits on the neighboring stand are substitutes, with $a_{t}<0$. Accordingly, if benefits rise with stand age, a harvest event on the neighboring stand causes an upward shift in the flow of amenity benefits (Fig. lb) because after this harvest the supply of amenity services from the neighboring stand drops so that the marginal value of amenities from the focal stand rises. Similarly, if benefits fall with stand age, harvesting nearby causes a downward shift in $\mathbf{a}(\cdot)$ (Fig. 1c) because the supply of amenities from the neighboriro stand increases so that the marginal value of amenities from the focal stand fails. If stand interactions create a complementary relationship, then the shifts in Figs. $1 b$ and $1 c$ would reverse. with $a_{t \tau}>0$. Shifts in amenity benefits quantify the effects of nearby harvesting on the scarcity of nontimber services in the geographic area surrounding the focal stand.

Now consider the singie-stand management for the case where amenity benefits rise with stand age $(a,(\cdot)>0)$ and the stands are substitutes in production of amenity values $\left(a_{t r}(\cdot)<0\right.$ : Fig. lb). Here, MBD, simply includes the addition to timber benefits at age $t, p V_{T}(\cdot)$, plus the amenity flow at $t$ : meanwhile, MOC, includes the direct opportunity cost of delaying timber benefits from the ith rotation and delaying all benefits from future rotations. $r\left(p V(\cdot)+N^{*}\left(i, \tau\left(i, T_{i}\right)\right)\right\}$, plus the cost of a reduced flow of future nontimber benefits due to a marginal shift in the rotation sequence on the focal stand relative to the exogenous sequence on the neighboring stand. $\left\{-N_{\tau}^{*}\right\}$. The direction of change in the value of future nontimber benefits-that is, the sign of $N_{-}^{*}$-depends on the sign of $a_{\tau}(\cdot)$ (see (4) and (6)). Therefore, with amenities rising with stand age and substitutability between stands, $-N_{T}^{*}$ represents an opportunity cost of delay in addition to those opportunity costs present when stands produce nontimber benefits independently. Here, because a harvest delay implies that the neighboring stand will be marginally older during future rotations, a decision to delay the current harvest implies that the future flow of nontimber benefits from the focal stand will be lower.

Figure 2 illustrates the implications of stand interactions with nontimber benefits rising with stand age and substitutability between stands. In Fig. 2, if the neighboring stand is nor clearcut during rotation $\mathbf{i}, \mathrm{MBD}^{\circ}$ and $\mathrm{MOC}^{\circ}$, respectively, identify the curves defined by (8). In this case, the intersection of $\mathrm{MBD}^{0}$ and $\mathrm{MOC}^{0}$ determines the optimum age for rotation $i$ at point A (Fig. 2). However, if the neighboring stand is ciearcut while the focal stand is at some age. $l_{1}$, then $\mathrm{MBD}_{i}$ and MOC, shift to MBD' and $\mathrm{MOC}^{\prime}$ after $t_{1}$ in Fig. 2 (cf. Figs. la and lb). These shifts in MBD and MOC occur because $a_{-}(\cdot)<0$ and the neighboring clearcut causes a nonmarginal decline in $\tau(\cdot)$. After a neighboring clearcut, MBD' 

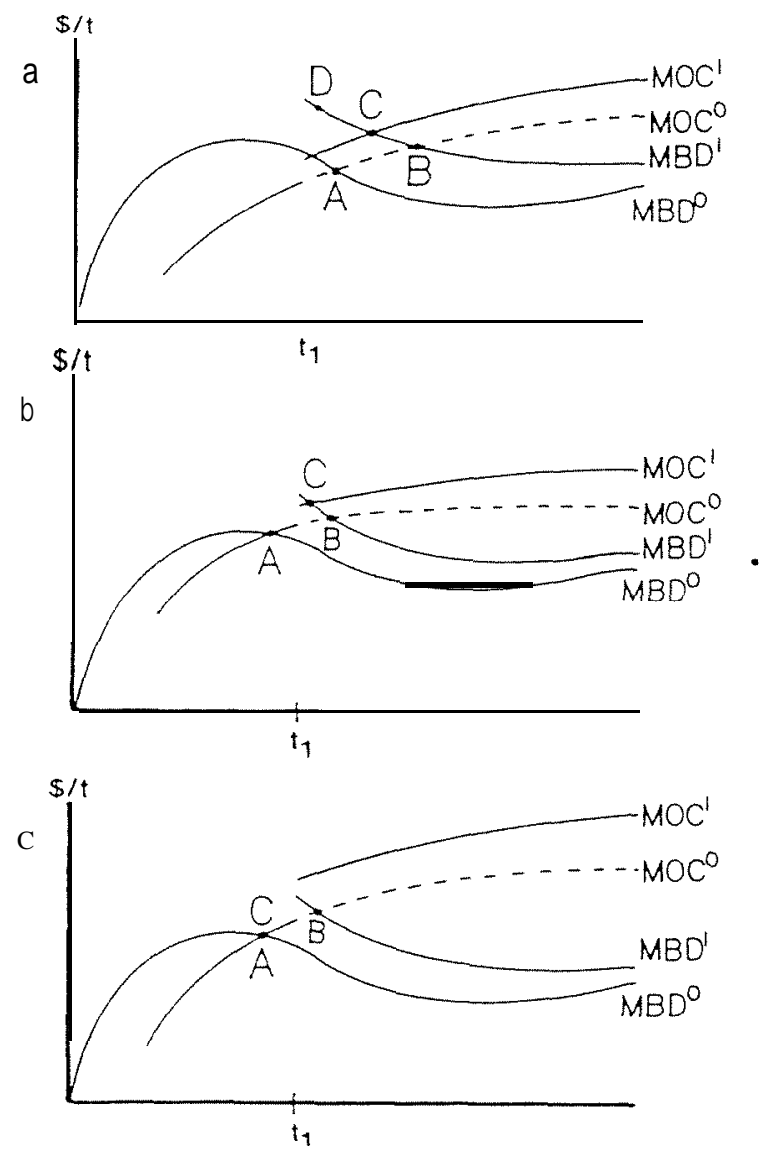

FiG. 2. Example solutions of the single-stand model for the optimal rotation age $T_{i}$, assuming nontimber benefits as in Fig. $\mathrm{lb}$. At the optimum $T_{i}$, the marginal benefit of delay equals the marginal opportunity cost of delay $(\mathrm{MBD}=\mathrm{MOC})$, where superscrip $* 0$ denotes curves when the neighboring stand is not clearcut by focal age I,. Note in panel a that a larger wealth effect could cause MOC' to intersect MBD' at D rather than at C.

and $\mathrm{MOC}^{1}$ may determine the optimum age for rotation $i$, such as at point $\mathrm{C}$ (Figure 2a).

The total differential of the optimum age $T_{i}$ reflects these shifts in marginal conditions as

$$
d T_{i}=\left[1 / N_{T T}^{*}(i, 0)\right]\left\{-a_{\tau}+\left(r N_{*}^{*}(i+\mathbf{1 . 0})-N_{\tau}^{*}(i+1,0)\right)\right\} \cdot d \tau,
$$

where $N_{T T}^{*}$ is negative by the second-order condition on an optimum rotation age. From (9), one sees formally that the impact of stand interactions on the optimum rotation age decomposes into two types of impacts, analogous to the substitution and income effects from utility theory. The substitution effect. indicated by $-a_{*}$, encourages managers to increase the rotation age, because $-a_{-}$is positive when stands are substitutes and $d \tau / N_{T T}^{*}$ is positive when the neighboring stand is clearcut. By increasing the rotation age. managers increase the separation in age 
between the focal stand and its neighbor, thereby mitigating local scarcity of nontimber benefits. In contrast. however, the "income" or wealth effect. indicated by $r N_{-}^{*}-N_{*-}^{*}$, discourages managers from increasing the focal stand's rotation age, because, formally, this term is negative for substitutable stands. Informally, the wealth effect discourages a harvest delay because the neighboring clearcut $(d \tau<0)$ increases the present value of future nontimber benefits on the focal stand. thereby raising the opportunity cost of delaying the receipt of those benefits. In general, a clearcut on the neighboring stand may either decrease or increase the rotation age $T_{i}$. Figure 2 illustrates three cases.

Using point $\mathrm{B}$ in Fig. 2a helps illustrate the substitution and wealth effects. First. a neighboring clearcut raises the value of the focai stand in producing nontimber benefits locally (Fig. lb). Thus, the neighboriro clearcut causes the marginal benefits of delaying the current harvest to rise (MBD shifts up), and the optimum rotation age increases from A to B (Fig. 2a) as the demand for nontimber benefits shifts to the focal stand. substituting away from the neighboring stand. The change from A to B is analogous to a substitution effect. Simultaneously, the future value of nontimber from the focal stand increases, thereby increasing the present value of wealth associated with the focal stand and increasing the marginal opportunity cost of a harvest. This wealth effect causes the optimum rotation age to decrease from $\mathrm{B}$ to $\mathrm{C}$ in Fig. $2 \mathrm{a}$.

As shown, Fig. 2a illustrates a situation where the substitution effect exceeds the wealth effect. However. the wealth effect may exceed the substitution effect whenever point A occurs after the neighboring clearcut (after focal stand age $t_{1}$ ) and the shifts in marginal conditions cause MOC' and MBD' to intersect at an earlier age. such as at a point like D (Fig. 2a).

Figure $2 b$ illustrates the second case, where the solution for an optimum rotation age $T_{\text {in }}$ may not be unique. Here, a local optimum occurs both before (point A) and after (point $\mathrm{C}$ ) the anticipated clearcut on the neighboring stand. If delaying until $\mathrm{C}$ provides a positive net present value (discounted sum of MBD MOC exceeds zero. based on empirical analysis), then ending the rotation at $\mathrm{C}$ rather than $\mathrm{A}$ is globally optimal; otherwise, A dominates $\mathrm{C}$.

The third case (Fig. 2c) illustrates that, if a discontinuity in the condition of the neighboring stand occurs late enough, the current rotation may have no optimum after the neighboring clearcut. Effectively, the discontinuity causes points $\mathrm{A}$ and $\mathrm{C}$ to coincide, because the wealth effect is great enough to push the optimum age back before the neighboring clearcut at age $t_{1}$ on the focal stand. If the neighboring clearcut had occurred earlier than shown in Fig. 2c, MBD' and MOC' might have satisfied the necessary conditions, resulting in a case such as that in Fig. $2 \mathrm{~b}$.

In some cases (not illustrated), management of the neighboring stand might motivate more dramatic shifts in management of the focal stand. First, if $\mathrm{MOC}^{0}$ exceeds $\mathrm{MBD}^{0}$ everywhere, then optimal management may set the rotation age at zero, holding the focal stand as a forest opening for wildlife (e.g., [20]). However, if a neighboring clearcut is anticipated at $t_{1}$, then $\mathrm{MOC}_{i}^{1}$ and $\mathrm{MBD}_{i}^{1}$ might satisfy the necessary conditions. Like Fig. 2b, this case involves two local optima, but with a more dramatic difference between the two optimal ages, one at (or near> age zero with the second at a much oider age. Thus, the manager might maintain a "forest opening" temporarily, perhaps for several (degenerate) "rotations." Then, once the neighboring harvests are more favorably staggered. the focal manager might resume timber production. 
Second, conditions (not illustrated) may exist under which nontimber benefits encourage maintaining the focal stand as mature forest, with $\mathrm{MBD}^{0}$ exceeding $\mathrm{MOC}^{0}$ everywhere so that "point $\mathrm{A}$ " occurs at a high, possibly infinite, age: however, a neighboring clearcut could cause MBD' to intersect MOC' from above so that a local optimum "point C" occurs at a smaller, finite age. These conditions might re-open a focal stand of "wilderness" for timber production.

Management on the focal stand might follow any sequence of harvests involving one or more of the above cases. The optimal sequence depends on how clearcuts on "the rest of the forest" are staggered, temporally and spatially, relative to the flow of timber and nontimber benefits from the focal stand. When stand interactions are significant. the single stand may alternate the character, quality, or quantity of both its timber and its nontimber outputs. This alternation might involve rotations that produce pulpwood, later rotations that produce sawtimber, and other rotations that involve early clearcuts with minor timber benefits. This simple model offers an intuitive, yet rigorous, framework that maintains the location-specific implications of stand interactions. The next section illustrates the model using simulation results.

\section{TIMBER AND WILDLIFE FORAGE CASE STUDY}

The case study examines the production of both forage biomass and timber. For simplicity, the analysis assumes that two landowners each hold one of two stands of equal size, the focal stand and the neighboring stand. The neighboring landowner manages for timber alone, prescribing a Faustmann rotation plan. In contrast, the focal landowner values both forage and timber. This scenario is analogous to situations faced by public managers in intermingled ownerships. In particular. one may imagine a case where a public ownership abuts a stand owned by a private, industrial timber corporation.

In the case study. the return to forage on the focal stand depends on the total forage production on both stands $(a=a(t, \tau))$. The focal stand's manager values forage production consistently with a wildlife production scenario, where big game require both forage and cover. The two stands define the relevant geographic area. Forage and cover are inversely related, so that maximum forage production implies minimum cover. The value of forage is net of the value of cover units. Also, the marginal value. $f$, per unit of forage decreases as availability of forage rises, increasingly displacing cover.

\section{Simulation Procedure}

One cannot solve the manager's objective (1) using a convenient "representative rotation," as in the Faustmann-Hartman case. A practical alternative is to use forward dynamic programming [11, pp. 270-273], terminating the dynamic program upon achieving a cyclical steady state.

To implement a dynamic programming algorithm, define $R(\tau(i, 0))$ as the present value of returns from rotation $i$, measured in dollars at the start of the rotation and given the neighboring stand age $\tau(i, 0)$; that is. $R(\cdot)$ simply denotes the sum of timber and nontimber benefits from rotation $i$, incorporating only the terms in braces in Eq. (1). Then one may segregate the rotations into an initial 
sequence and a sequence that comprises a cyclical steady state and thereby rewrite objective (1) as

$$
\begin{aligned}
N & =\max _{\left\{T_{1}\right\}} \sum_{i=1}^{\infty} R(\tau(i, 0)) \cdot \alpha_{1, i-1} \\
& =\max _{\{T\}} \sum_{i=!}^{k \cdot l} R(\tau(i, 0)) \cdot \alpha_{1, i-1}+\alpha_{1, k-1} \cdot \frac{\sum_{i=0}^{n} R(\tau(k+i, 0)) \alpha_{k, k+i-1}}{\left(1-\alpha_{k, k+n}\right)},
\end{aligned}
$$

where the first $k 1$ rotations precede the steady state, the second term in (10b) quantifies the present value of all rotations occurring after the steady-state cycie begins, and the $\alpha$ 's summarize discount factors as defined in (7). The steady-srate cycle begins with the $k$ th rotation and involves $n$ harvests, with the condition of the neighboring stand identical at the beginning and end of the steady-state cycle, $s$ o $+(k, 0)=\tau(k+n+1,0)$. Therefore, the second summation term in (10b) quantifies the present value of a single iteration through the steady-state cycle, valued at the beginning of that cycle; this value repeats so that the discount factor in the denominator (i.e., $1-\alpha_{k, k+n}$ ) converts that value to present value for an infinite time horizon. Thus, the last term in $(10 \mathrm{~b})$ is analogous to the "representative rotation" format of the independent-stands mode1 [7, 12]. The single-stand focus enables both this simple formulation (10) and explicit calculation of the cyclical steady state.

Upon confirming the steady state's beginning, the forward dynamic programming algorithm for (10b) simply adds the value of the last term in (10b) to the value of the first $k-1$ rotations. Since appiied dynamic programs must increment stand ages in finite intervals, in practice a cyclical steady state will occur in a finite, though possibly large. number of program steps. Results reported below derive from a dynamic program with the minimum increment in stand ages set to one year, thereby approximating a continuous-time solution reasonably well.' That program numerically evaluates the integrand for nontimber benefits, a component of $R(\cdot)$ given explicitly in (1), using an extended trapezoidal rule with a fractional precision of 0.0001 for convergence within 16 steps [27, p. 111].

\section{Empirical Basis}

The case study relies on data used for planning analyses on the Lolo National Forest in western Montana (see Swallow et al. [31]). The timber model assumes zero marketable volume if $t \leq 20$ and then follows a logistic growth function

$$
V(t)=K /\left(1+e^{\Omega-\Theta t}\right), \quad t>20
$$

where $K$ is a carrying capacity of 15.055 thousand board feet per acre (mbf/acre) and the parameters $\Omega$ and $\Theta$ are 6.1824 and 0.0801 , respectively [31]. The forage

'Bowes and Krutilla [1-3] used a minimum age increment of 30 years to make their dynamic program practical. 
production function is

$$
g(t)=b_{0} \cdot t \cdot e^{-b_{1} \cdot t}
$$

where quantity $g$ is measured as animal-unit-months (aum) per year. with parameters $b_{0}$ and $b_{1}$ equal to 0.0770 and 0.0850 . respectively [31]. Forage production rises to a peak at age 12 and then asymptotically fails to zero.

The simulation holds timber prices, p. constant at $\$ 60.00$ per mbf. consistent with the role of either timber stand in a competitive timber market. However, the value of forage for wildlife depends on local ecological conditions as well as on the value of game to hunters. Thus. the simulation assumes that the marginal value, $f$, of forage follows the function

$$
f(t, \tau)=f_{0} e^{-\Gamma \cdot[g(r)+g(\tau)]}
$$

where the parameter $f_{0}$ represents the upper limit on the value of forage and the parameter $\Gamma$ represents the rate at which valuation adjusts to the availability of forage for wildlife in this geographic area. In an actual application, the parameters in (13) reflect a combination of demand for hunting sites with various forage/cover ratios, perhaps derived from demand for wildlife and wildlife's response to forage and cover supplies. The simulations assume parameters $f_{0}$ and $\Gamma$ are $\$ 30 /$ aum and 2, respectively, yielding marginal forage values between $\$ 8.00$ and $\$ 29.00$ per aum over a plausible range of ages $t$ and $\%$

The simulation exercise combines the forage production function (12) and the marginal valuation function (13) to define three different amenity benefit functions. Each amenity benefit function illustrates a different form of production externalities. pertaining to the forest manager's ability to appropriate nontimber benefits or pertaining to the nature of stand interactions. For each of the three amenity functions, Fig. 3 maps iso-value lines as a function of the ages of the two stands.

a

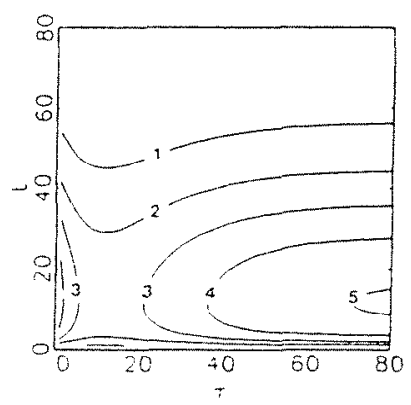

b

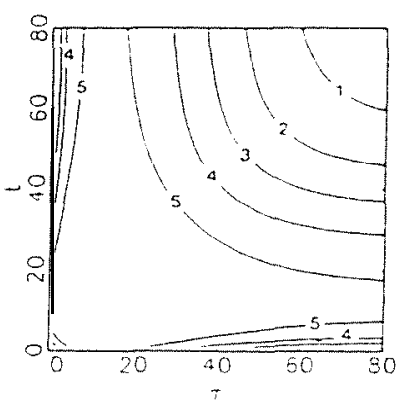

C

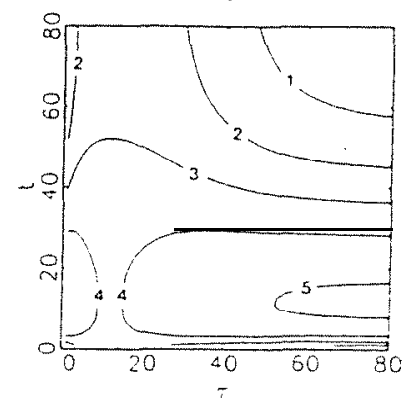

FIG. 3. Iso-value lines for amenity benefits for three cases. based on the forage growth function (12) and value function (13). The cases are defined in the text for Eqs. (14)-(16), with the degree to which the focal manager considers wildlife benefits from the neighboring stand as follows: (a) Focal wildlife only, $a(t, \tau)=g(t) \cdot f(t, \tau) ;(b)$ full wildlife, $a(t, \tau)=[g(t)+g(t)] \cdot f(t, \tau) ;(c)$ partial wildlife of neighbor, $a(t, \tau)=\left[g(t)+\frac{1}{2} g(t)\right] \cdot f(t, \tau)$. Numerical labels on the iso-value lines Indicate the dollar value flow of nonimber benefits. $a()$. 
In the first case, the owner of the focal stand benefits only from forage actually produced on the focal stand, although the neighboring stand affects the scarcity value of wildlife forage. This situation generates the case "focal wildlife only," with

$$
a(t, \tau)=g(t) \cdot f(t, \tau),
$$

which ranges from SO.12 to over $\$ 5.00$ per acre per year over a plausible range of stand ages $t$ and $\tau$ (Fig. 3a). In this case, Fig. 3a shows that higher forage benefits occur when the focal stand is relatively young.

In the second case, some relationships between landowners might allow the focal landowner to appropriate nontimber benefits from both stands. For example, wildlife may roam evenly across the stands or the neighbor may grant the focal landowner free access to hunt. Alternatively, a public agency may own the focal stand and strive to maximize market returns from the public land plus the total nonmarket benefits across the forest, as is consistent with efficiency arguments for public forest management with externalities (e.g. [19]). This situation generates the case of "full wildlife." with

$$
a(i, \tau)=[g(t)+g(\tau)] \cdot f(t, \tau) .
$$

Figure 3b illustrates wildlife benefit function (15), showing high forage values when either stand is young.

In the third case, the focal landowner may obtain partial benefit from forage on the neighboring stand, perhaps due to a nonuniform pattern of habitat use by wildlife. Since wildlife are a fugitive resource, hunters may not require physical access in order to benefit partially from neighboring forage. This case is "partial wildlife from neighbor," with

$$
a(t, \tau)=[\mathrm{g}(\mathrm{t})+0.5 \cdot g(\tau)] \cdot f(t, \tau) .
$$

In (16), forage on the neighboring stand is equivalent to only half an aum on the focal stand, an arbitrary choice selected for illustrative purposes only. Figure $3 \mathrm{c}$ illustrates benefit function (16), which values younger ages on the focal stand more heavily than under focal wildlife only (Fig. 3a).

The simulations evaiuate objective (10) using the Forest Service's standard discount rate of 0.04 . To examine the influence of initial conditions, simulations determine management plans for a range of initial ages on the neighboring stand, $\tau(1,0) \in\{0,15.30,45,60\}$. Finally, consistent with the selected parameters and the neighbor's timber-only management, simuiations assume neighboring clearcuts always occur at age 76 .

For comparison, one could calculate the "Hartman rotation age" [12] for multiple use on an independent stand. For that case, Swallow et al. [31] show that, with a constant forage value of $\$ 20$ per aum, these data imply a global optimum at 73 years, with a second local optimum at 26 years. These "Hartman ages" represent the independent-stand model in the sense that $\$ 20$ approximates the mid-range of forage values used here for $f(t, \tau)$ in $(13)-(16)$.

\section{Results}

Results are displayed in Table I. Table I reveals that single-stand management with stand interactions may produce a range of qualitatively different harvest 
TABLE ]

Optimal Programs for the Focal Stand for Three Cases of Wildlife Benefit Functions and Various Initial Conditions on the Neighboring Stand"

\begin{tabular}{|c|c|c|c|}
\hline $\begin{array}{c}\text { Initial age on } \\
\text { neighbor's stand } \\
\qquad(-(1,0))\end{array}$ & $\begin{array}{l}\text { Transition } \\
\text { sequence } \\
\left(T_{1}, i<k\right)^{c}\end{array}$ & $\begin{array}{l}\text { Steady-state } \\
\text { cycle } \\
\left(T_{i}, l \geq k\right)\end{array}$ & $\begin{array}{c}\text { Neighbor's age } \\
\text { at cycle's start } \\
(-(k, 0), \\
-(k+n+1,0), \ldots)\end{array}$ \\
\hline \multicolumn{4}{|c|}{ Case 1: Focal wildlife only } \\
\hline & 26 & 26666967 & 26 \\
\hline 15 & 286768 & 26666967 & 26 \\
\hline 30 & None & 26676867 & 30 \\
\hline 45 & 6324 & 26676867 & 56 \\
\hline 60 & 3028 & $26 \quad 666967$ & 42 \\
\hline \multicolumn{4}{|c|}{ Case 2: Full wildlife } \\
\hline 0 & 2774 & 7775 & 25 \\
\hline 15 & 23717272 & 7775 & 25 \\
\hline 30 & None & 76 & 30 \\
\hline 45 & 67747172 & $\overline{77} 75$ & 25 \\
\hline \multirow[t]{2}{*}{60} & 686869737172 & 2775 & 25 \\
\hline & 29 Case 3: Parti & $\begin{array}{l}\text { wildlife of neighbor } \\
\begin{array}{ll}25 & 68 \quad 72 \quad 727271\end{array}\end{array}$ & 29 \\
\hline 15 & 2771 & 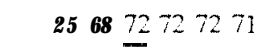 & 37 \\
\hline 30 & 71 & $25 \mathbf{6 8 7 2} 727271$ & 25 \\
\hline 45 & None & $25 \quad 68 \quad 72 \quad 72 \quad 72 \overline{71}$ & 45 \\
\hline 60 & 676771 & $\begin{array}{llllll}25 & \overrightarrow{68} & 72 & 72 & 72 & 71\end{array}$ & 37 \\
\hline
\end{tabular}

${ }^{a}$ All values in years. The neighboring stand is cut on a Faustmann rotation of 76 years.

${ }^{b}$ An underbar indicates the first rotation following the transition sequence.

"The steady-state cycle begins with the $k$ th rotation and lasts for $n$ rotations, where. for each row. $\mathbf{k}=1$ is the number of rotation ages listed in the second column and $n$ is the number of rotation ages listed in the third column.

plans, depending on the initial conditions and on the manager's wildlife benefits. First, any number of rotations might constitute the transition to the steady-state cycle. Second, since the neighboring stand follows the Faustmann rotation plan, the steady-state cycle must cover a multiple of 76 years. Third, the transition sequence and the steady state might include rotations that produce sawtimber, with ages near the Faustmann age, and rotations that emphasize nontimber. with rotations substantially shorter than the Faustmann age (but. not surprisingly. near the second local optimum Hartman age). Fourth. for each wildlife benefit function, the steady-state cycles are similar across the range of initial conditions for $\tau$.

For each case, Fig. 4 portrays how a steady-state cycle staggers focal harvests with neighboring harvests. In Fig. 4, diagonal lines track the ages of both stands through that cycle, with clearcuts causing discontinuities. Figure 4 overlays this age track on the iso-value lines for wildlife (Fig. 3).

Focal wildlife only. In the first case (14), the steady-state cycles (Table I) produce sawtimber for three rotations, which are shorter than the comparable 
a

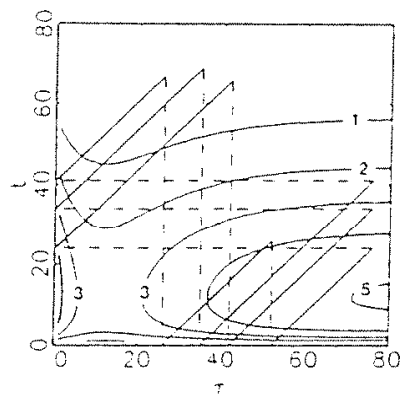

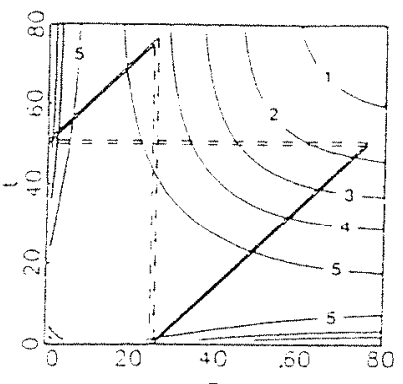

$c$

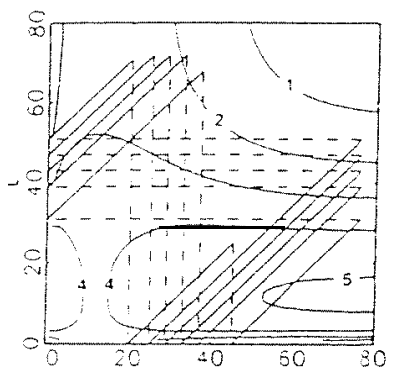

FIG. 4. Overlay of selected steady-state cycles on the iso-value lines for wildife in each simulated case (Table I). (a) Focal wridlife only, (b) full wildlife, (c) partial wildlife of neighbor. The diagonal line segments show the age of the focal stand relative to the age of the neighboring stand during a steady-state cycle. Following the upper-right end of the diagonal segments. the vertical and horizontal dashed lines indicate an instantaneous fall in one stand's age due to a clearcut of that stand.

Faustmann or Hartman ages. and emphasize wildlife forage with poletimber for a fourth. very short. rotation. Tho transition sequence may establish the steady state with either long or short rotations (Table I).

Furthermore, in this case. Fig. 4a shows (for $r(1.0)=0$. 15. or 60: Table I) ${ }^{8}$ that steady-state harvests are staggered to mitigate for periods of low forage availability. For the three longer rotations in this steady state (those rotations reaching higher on the $t$-axis), the focal stand is moving out of the young ages of high forage output as the neighboring stand is clearcut and becomes the forage producer, so that a sawtimber harvest is timed to impose a relatively low opportunity cost of foregone wildlife forage' (Fig. 4a). The advantage of staggering is clearly revealed by the timing of the short. 26-year rotation. which starts and ends while the neighboring stand is in "middle age" $(26<\tau<52)$. During that short rotation the focal stand produces amenities under conditions of high value, generally $\mathrm{a}(\cdot)>3$ (Fig. 4a). Moreover, this timing sets the three longer rotations so that, during their first several $(\leqslant 26)$ years, the focal stand produces forage under conditions of even higher value, with $a(\cdot)>3$ and often a( $\cdot)>4$ (Fig. 4 a).

Full wildlife. In the second case (15), the steady-state cycle mimics timber-only management, but this plan may mitigate for cover deficits on neighboring (private) land by including rotations longer than the timber-only optimum (Table I, Fig. 4b). In this case, the average, steady-state rotation is longer, allowing managers to capture wildlife forage benefits available when the focal stand is relatively old but its neighbor is young, and vice versa (Fig. 4b). Still, the transition sequence varies greatly with the initial condition of the neighboring stand.

Partial wildlife from neighbor. In the third case (16), the steady-state cycle includes one wildlife-poletimber rotation and five sawtimber rotations that are four to eight years shorter than the Faustmann age (Table I). The transition may emphasize either wildlife or timber (Table I). In steady state. the manager staggers

"These simulations produce the same steady-state sequence: however, the "first" rotation in that sequence may differ for different values of $T(1.0)$.

${ }^{*}$ The clearcul occurs so that $i=0$ when $i$ is at early middle age so $a(\cdot)$ will be mostly above rso-value 3 in the next, focal rotation: see Fig. 4 a. 
production of wildlife forage and cover so that the neighboring harvests occur as the focal stand enters older ages. The manager again accomplishes the wildlife-poletimber rotation when wildlife opportunities are high. thereby setting the five longer rotations so that their first several $(\leqslant 31)$ years also occur while forage values are consistently high $(a(\cdot) \geqslant 4$; Fig. 4c). Relative to the focal-wildlife-only case, the "ridge" of high wildlife benefits is broader across ages on the neighboring stand, as long as the focal stand is young (compare portions of Figs. 3a and $3 c$ where $\tau>20$ and $t<30$ ). This type of wildlife value function allows managers more flexibility to fine tune a multiple-use plan. Therefore, the more complicated steady state in Fig. $4 \mathrm{c}$ is less surprising.

Comparison across the three cases reveals a fifth, generic result: in this case study, as wildlife benefits show a progressively less well-defined ridge of high value (order Fig. 3 as 3b, 3a, 3c), the steady state becomes more complicated (Fig. 4) as managers optimize the plan.

\section{RELATION TO FOREST-LEVEL MANAGEMENT AND MODELS}

The foregoing illustrates the model where management on a neighboring stand remains exogenous. The basic analytical process does nor rely on the assumption of Faustmann management by the neighbor or the particular type of nontimber benefits. While this approach is useful for many policy contexts, future research is needed to extend the model for application where a single manager controls several stands. Such an extension is straightforward, conceptually," but the "curse of dimensionality" may constrain applications.

Bowes and Krutilla (B-K) $[2,3]$ offer one type of extension to the forest level. However, the present model, aside from its single-stand scope. is distinct because it clearly attributes stand interactions to specific locations. This distinction is subtle, but significant. First. the B-K conceptual model optimizes the distribution of ages throughout the forest. A single age-class may incorporate one or several nonadjacent stands. Second, for empirical illustrations, B-K define a dynamic program that retains the locational identity of stands. However, as with their conceptual model, only the mix of stand ages determines the nontimber benefits. independent of location [3, p. 1331. The age-class approach obscures substitution and wealth effects relevant to the plan-implementation level. Bowes and Krutilla help managers optimize a forest's age class distribution, while the single-stand model provides additional insights to improve plan implementation.

\footnotetext{
${ }^{10}$ The forest-level objective function simply indexes rotation ages and the vector of "neighboring" ages for the applicable stand. Based on $(10 \mathrm{a})$, the objective becomes $\mathrm{N}=\max _{\left(T_{s i}\right)} \sum_{s=1}^{S} \sum_{i=1}^{\infty} R_{s}\left(\tau_{s}(i, 0)\right)$ $\alpha_{1,5,1-1}$, where $s$ indexes the location-specific stands; $S$ stands constitute the forest: $T_{s t}$ substitutes for $T_{1}$ throughout the paper, including the definition of $\alpha$ in $(7) ; \Sigma_{s}$ is a vector of ages for stands affecting stand $s ;$ and $s$ ranges up to stand $S+P$. where $P$ is the number of relevant stands outside the manager's control. The B-K model could be extended similarly by indexing elements of their age-class vector for location. However, since B-K [2. 3] determine optimal acreages to harvest, their model may fractionate locations, which may be difficult to formulate within their notatron, and which motivates heuristic approaches $\{17,25,29\rfloor$ to optimizing plans for operational implementation on stands. Again. the difference between this more general model and a more general B-K model IS subtle. Hopefully, the present approach facilitates intuitive comprehension of stand interactions and consideration of lands in adiacent ownerships. Lastly, the optimaliry conditions for the extended model would include terms for feedback of each $T_{s 1}$ on future $T_{31}$ 's for the other stands (left to the reader).
} 
Bowes and Krutilla [1-3] offer conceptual breadth and. especially, major practical advantages for optimizing at the forest level. Meanwhile, the single-stand model suffers some oversimplifications. However, like its predecessors, this singlestand model offers important conceptual advantages.

First, the single-stand model provides an intuitive explanation for forest-level considerations, especially concerning inter-stand trade-offs associated with substitution and wealth effects. Second, results are highly specific. revealing many forest-level impacts on management of a single stand and indicating the harvest schedule for a specific location. Third. the focal-stand approach offers insights to criteria for staggering neighboring harvests. Fourth, the model anticipates unresoived policy issues, at both conceptual and empirical (operational and plan-implementation) levels.

Conceptually, the model may motivate a framework for analysis of a two-person game, where each player owns one stand. While a two-stand model might still limit applications, a game-theoretic analysis might offer insights for negotiating cooperative agreements that encourage neighboring public and private landowners to optimize multiple-forest benefits. Munro [22, 23] offers examples for renewable resources, especially fisheries.

Empirically, the model may óffer insights for forest managers who currently rely on heuristic methods to optimize a forest-level plan. For example, Roise [29] develops an approach to constrain timber-only optimization so that a minimum time separates adjacent harvests and promotes nontimber values. The present model permits assessment of the optimal staggering of neighboring harvests. thereby offering insights that might help managers select adjacency constraints. The model also offers a tool with which heuristic foresr-level models might incorporate landscape ecology [8, 32]. Landscape ecologists suggest that interactions between any two stands may depend on ages of still other, nearby stands, dependencies that could be captured if $\tau$ represents a vector of stand ages. For example, two stands may interact significantly only when a third, intervening stand provides habitat appropriate to a wildlife corridor [8,321. One might also assess such concerns by modeiing the single stand when neighboring management affects a measure of spatial pattern [32] that, in turn, represents "the condition of the rest of the forest." These types of analysis, and their potential policy contributions, arise from the model's simple and explicit tie between the stand-level harvest decision and the stand's locational identity.

The case with both multiple ownership and multiple resource production demands further extensions to adequately capture its complexity. Managers of public lands, in this case, often use linear programming (LP) [17, 25] to coordinate multiple, independent, single-stand problems, with constraints intended to promote nontimber services. However, by using Fautmann-Hartman analytics to define the complement of management activities allowed for each stand (i.e., the columns in the LP matrix), that standard approach overlooks stand-level substitution and wealth effects, with concomitant losses.

\section{CONCLUSIONS}

This paper develops a single-stand model that allows for interactions with neighboring stands within the forest. The model provides a simple, intuitively 
tractable approach to the multiple-use, multi-stand forestry problem. Results show that stand interactions, by creating substitution and wealth effects, may lead managers to alter harvest schedules by shifting the schedule on one stand relative to the schedule on a neighboring stand, thereby gaining from the substitutability of alternative stands that produce nontimber services. Optimal management may allocate a stand to different roles over time, rotating a stand's emphasis across subsets of timber and nontimber benefits, rather than establishing a more specialized, time-invariant use. Simulations illustrate timing of sequential. neighboring harvests to capture higher nontimber values.

The focal-stand approach to stand interactions elucidates analysis of the critical spatial dimension of forest management. Although simple. the analysis provides a rich collection of results. First the optimal program is, generally. a sequence of nonconstant rotations. Second, the condition of the adjacent stand(s), and expectations regarding its management, have a dramatic impact on management prescriptions in the short run. Third, the form of the stand interactions, including managers' objectives relative to nonmarket contributions from adjacent land (e.g., wildlife, biodiversity, or visual quality), may alter the optimal plan dramatically. The focal-stand approach enables development of these results in surprising depth.

Finally, standard pianning techniques for public lands fail to account for management on adjacent lands, despite widespread private impacts on public lands. Planning analysis that considers management on private lands might improve public benefits over the current responses, such as ad hoc moratoria on public land management [18, 33].

Simiiariy, managers of private nonindustrial forests likely consider conditions on adjacent lands. For example, hunting clubs may choose whether to harvest timber based, in part, on whether neighboring lands already provide cover or whether those lands provide forage. The typical Faustmann-Hartman analyses fail to capture such important aspects of the real complexity of forest management.

Future research might resolve further the model's potential contribution to conceptual and empirical policy applications. However, the single-stand model above, with its consideration of neighboring forest conditions and its explicit linkage between the stand-level harvest decision and the stand's locational identity, offers an opportunity to develop intuitive insights that are elusive with more realistic and less tractable forest-level optimization models.

\section{REFERENCES}

1. M. D. Bowes, "Economic Foundations of Public Forestland Management, Resources for the Future," Quality of the Environment Division, Discussion Paper D-104 (Jan. 1983).

2. M. D. Bowes and J. V. Krutilla, Multiple use management of public forestlands, in "Handbook of Natural Resource and Energy Economics" (A. V. Kneese and J. L. Sweeney, Eds.), Vol. II, North-Holland. Amsterdam (1985).

3. M. D. Bowes and J. V. Krutilla, "Multiple-Use Management: The Economics of Public Forestlands." Resources for the Future, Washington, DC (1989).

4. S. Calish, R. D. Fight, and D. E. Teeguarden, How do nontimber values affect Douglas-fir rotations? J. Forest. 76, 217-221 11978).

5. C. W. Clark. "Mathematical Bioeconomics: The Optimal Management of Renewable Resources," Wiley, New York (1976).

6. M. Clawson. Multiple-use considerations, $m$ "Managing Public Lands in the Public Interest" (B. C. Dysart. III. and M. Clawson, Eds.), Praeger, New York (1988). 
7. M. Faustmann, On the determination of the value which forest land and immature stands pose for forestry (1849), in "Martin Faustmann and the Evolution of Discounted Cash Flow" (M. Gane, Ed.), Oxford Institute, Oxford (1968).

8. J. F. Franklin and R. T. T. Forman, Creating landscape patterns by forest cutting: Ecological consequences and principles, Landscape Ecoi. 1, 5- 18 (1987).

9. M. L. Franzese, National Forest planning: Looking for harmony, in "Managing Public Lands in the Public Interest" (B. C. Dysart, III. and M. Clawson. Eds.), Praeger. New York (1988).

10. R. H. Giles. "Wildlife Management," Freeman. San Francisco (1978).

11. D. A. Haith, "Environmental Systems Optimization," Wiley, New York (1982).

12. R. Hartman, The harvesting decision when a standing forest has value, Econom. Inquiry 14. $52-58$ (1976).

13. T. Heaps, The forestry maxumum principle, J. Econom. Dynamics Control 7, 131-151 (1984).

14. W. F. Hyde. "Timber Supply, Land Allocation. and Economic Efficiency," Johns Hopkins Univ. Press. Baltimore, MD (1980).

1.5. D. H. Jackson, "The Microeconomics of the Timber Industry," Westview Press, Boulder, CO (1980).

16. D. H. Jackson, Economic suitability of lands for timber production: A proposed rule of reason. Public Lund Law Rev. IO., 73-90 (1989).

17. $\mathrm{K}$ N. Johnson and $\mathrm{H}$. L. Scheurman. Techniques for prescribing optimal timber harvest and investment under different objectives: Discussion and synthesis, Forest Sci. Monograph 18 $(1977)$.

18. T. Kenworthy, Official cuts against gram, fights U.S. timber quota, Washington Post (Nov. 12, 1991).

19. J. V. Kutilla and J. A. Haigh, A integrated approach to National Forest management. Enuiron. Law 8, 373-415 (1978).

20. M. S. Lenarz. Economics of forest openngs for white-lailed deer, Wildife Soc. Bull. 15. $568-573$ (1987).

21. A. F. McQuillan, The problem with economics in forest planning: An overvew at three levels, Public Lund Law Rev. 10. 55-72 (1989).

22. G. R. Munro, The optimal management of transboundary renewable resources, Canad. J. Econom. 12. $355-376$ (1979).

23. G. R. Munro, The optimal management of transboundary fisheries: Game theoretic considerations, Natur. Resource Modeling 4. 403-426 (1990).

24. D. H. Newman, "The Optimal Forest Rotation: A Discussion and Annotated Bibliography," General Technical Report SE-48, USDA Forest Service, Southeastern Experiment Station (1988).

25. G. L. Paredes V. and J. D. Brodie, Activity analysis in forest planning, Forest Sci. 34, j-18 (1988).

26. G. L. Paredes V. and J. D. Brodie. Land value and the linkage between stand and forest level analyses, Land Econom. 65, 158-166 (1989).

27. W. H. Press, B. P. Flannery, S. A. Teukolsky, and W. T. Vetterling, "Numerical Recipes: The Art of Scientific Computing," Cambridge Univ. Press, New York (1986).

28. W. J. Reed, Optimal harvesting models in forestry management-A survey, Narur. Resource Modeling 1, 55-79 (1986).

29. J. P. Roise, Multicriteria nonlinear programming for optimal spatial allocation of stands, Forest Sci. 36. 487-501 (1990).

30. D. L. Snyder and R. N. Bhattacharyya, A more general dynamic economic model of optimal rotation of multiple-use forests. J. Environ. Econom. Management 18, 168-175 (1990).

31. S. K. Swallow, P. J. Parks, and D. N. Wear, Policy-relevant nonconvexities in the production of multiple forest benefits, J. Environ. Econom. Management 19, 264-280 (1990).

32. M. G. Turner, Landscape ecology: The effect of pattern on process, Annu. Rev. Ecol. System 20, 171-197 (1989).

33. USDA Forest Service. Open letter from Forest Supervisor. Orville Daniels, to the public. file designation: 1920, Dated Sept. II, 1991, USDA Forest Service, Lolo National Forest, Building 24, Fort Missoula. Missoula, MT. 